\title{
How NaÏve Realism Can Explain Both THE PARTiCUlarity AND THE GENERALITY OF EXPERIENCE
}

\begin{abstract}
Visual experiences seem to exhibit phenomenological particularity: when you look at some object, it - that particular object - looks some way to you. But experiences exhibit generality too: when you look at a distinct but qualitatively identical object, things seem the same to you as they did in seeing the first object. Naïve realist accounts of visual experience have often been thought to have a problem with each of these observations. It has been claimed that naive realist views cannot account for the generality of visual experiences, and that the naïve realist explanation of particularity has unacceptable implications for self-knowledge: the knowledge we have of the character of our own experiences. We argue in this paper that neither claim is correct: naïve realism can explain the generality of experiences, and the naïve realist explanation of particularity raises no problems for our self-knowledge.
\end{abstract}

\section{Introduction}

Since the demise of logical positivism, it has been a tenet of analytic philosophy that we must distinguish the metaphysics of a domain from the epistemology of that domain. But when it comes to debates about the nature of visual experience, the two are closely intertwined. Debates about the nature of visual experience often appeal to claims about the phenomenology of visual experience in support of particular views, so the kind of knowledge we have of the phenomenology of our own visual experiences plays a role in philosophical theorising about the nature of those experiences. And some have thought that the kind of knowledge it is in principle possible for us to have of the phenomenology of our own 
visual experiences sets constraints on an account of the nature of visual experience.

Here we consider how these issues play out in debates about the particularity and generality of visual experience. Some of our visual experiences seem to exhibit phenomenological particularity: when you look at this apple, it - that particular thing - looks some way to you. But experiences exhibit generality too: when you look at a distinct but qualitatively identical apple, things seem the same to you as they did in seeing the first apple. In $\$ \$ 2-4$ we set out particularity and generality in more detail, and in $\$ 5$ we spell out how, contra to what some have supposed, a naïve realist can account for both particularity and generality. Our goal is not to motivate naïve realism, or to argue that a naive realist can explain particularity and generality better than other approaches, but just to show that, contra to what some have supposed, a naïve realist can account for both particularity and generality.

In spelling this out we end up with a view we call naïve realist particularism. One consequence of this view is that experiences of distinct particulars can differ phenomenologically, even if that difference cannot be detected by introspection. But now it looks like the naïve realist particularist is committed to a claim about epistemology that some have found problematic: that there are aspects of phenomenology which are necessarily introspectively inaccessible.

Some naïve realists would embrace such an implication. But in $\$ 6$ we argue that the naive realist particularist is not committed to there being any aspects of phenomenology which are necessarily introspectively inaccessible. Understanding why this is so can help us get a clearer view on the resources of naive realist theories of visual experience, and on the character and limits of the kind of knowledge we have of the phenomenology of our own visual experiences.

\section{Phenomenological Particularity}

Consider a perceiver, Jaya. She glances over towards her desk and sees on it her mid-morning snack: an apple. There's nothing abnormal about the perceptual conditions or situation, and there's nothing abnormal about Jaya's perceptual capacities. This is not a "bad case", it is a straightforward 
veridical visual perception: she simply sees the apple for what it is. She thinks, "I'm going to eat that", making reference in her thought to the very apple in question.

Jaya has a visual experience of a particular entity: a particular apple, not just some apple or other but that one. Her experience thus 'has particularity' (Soteriou, 2000, p.174). Further, it is plausible to suppose that the particularity of Jaya's experience is reflected in its phenomenology, that it exhibits phenomenological particularity. ${ }^{1}$ We can see that this is plausible by observing that the following are natural or intuitive characterizations of the phenomenology of Jaya's experience:

(1) It visually appears to her as if that apple is there

(2) It visually appears to her as if that apple is red

(3) That looks red to her

Furthermore, that these are natural or intuitive characterizations of the phenomenology of Jaya's experience not only makes it plausible to suppose that it exhibits phenomenological particularity, but phenomenological particularity of a certain form. For consider the following characterizations of the phenomenology of Jaya's experience:

(4) It visually appears to her as if there is an apple there

(5) It visually appears to her as if there is a red apple there

(6) Something looks red to her

These seem to leave something out. It is not just that the phenomenology of Jaya's experience is of a particular, some particular or other: it is not just that it exhibits what we can call generic phenomenological particularity. The idea we are trying to capture, as Martin (2002) puts it, is that 'the very object one is perceiving is an aspect of the phenomenology of one's experience' (p.196). Thus, the very particular that Jaya is perceiving (that, the apple) is an aspect of the phenomenology of her experience: it exhibits what we call specific phenomenological particularity. This is why (1)-(3) seem like more faithful characterizations of the phenomenology of Jaya's experience than (4)-(6) taken on their own.

${ }^{1}$ C.f. Schellenberg (2016), p.28. 
This is our starting point: that Jaya's experience exhibits specific phenomenological particularity, and more generally that some of our visual experiences of particulars exhibit specific phenomenological particularity. ${ }^{2}$ (We'll now drop the qualification 'specific', and mean by 'phenomenological particularity' specific phenomenological particularity unless otherwise stated).

One might think that Jaya's experience doesn't exhibit phenomenological particularity, and that (1)-(3) aren't natural or intuitive characterisations of the phenomenology. In response to such scepticism one option is to try to find some further reason for thinking that some of our visual experiences exhibit phenomenological particularity. Perhaps we can operationalise the role that visual phenomenology plays in our cognitive lives and argue that unless some of our visual experiences exhibited phenomenological particularity, then visual phenomenology wouldn't be able to play that role. Perhaps that role is the role of explaining our conception of a mindindependent world (Campbell 2002), or more generally, the role of putting us in touch with the world (McDowell 1994). This would be a way of motivating our starting point: that visual experience exhibits phenomenological particularity.

We won't pursue this option here. Instead, we will take our initial datum for granted. But note that one reason for being a sceptic about our starting point is that one thinks it is ruled out by the generality of experience. That is, one might think that visual experiences cannot exhibit phenomenological particularity given certain possibilities connected with the generality of experience: for instance, the possibility of there being an experience of a qualitatively identical but numerically distinct particular which Jaya cannot discriminate from her current experience. We are sensitive to this reason for scepticism, but it will take some work to turn this thought into an argument against the claim that visual experiences exhibit phenomenological particularity. We take on this task in the latter part of this essay. Our aim is to show why these possibilities do not tell against visual experience exhibiting phenomenological particularity. To that extent, the argument of the paper can be seen as removing one reason for rejecting our starting point.

${ }^{2}$ We do not intend this as a claim about all visual experiences. 


\section{Phenomenological Particularity and Naïve Realism}

Let naïve realism be the view that the visual experiences had in genuine cases of visual perception are fundamentally constituted, at least in part, by non-representational perceptual relations of conscious acquaintance between perceiving subjects and aspects of the mind-independent world. This is not intended merely as a view about the metaphysical structure of experience, but also about its phenomenology (Logue, 2012, pp.211-212). Thus, according to the naïve realist, the phenomenology of experience, too, is constituted, at least in part, by acquaintance between perceiving subjects and aspects of the mind-independent world. On this view, such aspects of mind-independent reality are presented in experience, and thereby constitutively shape the contours of consciousness (Martin 2004): the phenomenology of an experience is as it is, at least partly because of, or in virtue of, the nature and character of the aspects of the mind-independent world involved in the experience. In terms of the phenomenologyconstituting objects of acquaintance, here we'll focus mainly on particulars: including particular objects and instances of qualities. But that is not to say that the naïve realist must hold that only particulars are presented in experience. ${ }^{3}$

We can frame the project of explaining phenomenological particularity as follows: Why is it that the particularity of Jaya's experience - that it is of that - is reflected in the phenomenology of her experience? Naïve realism looks to provide a straightforward answer: The phenomenology of Jaya's experience is partly constituted by her being presented with that thing (the apple). And it - the very particular in question - is part of what constitutively shapes the contours of her conscious experience. That's why her experience of the apple exhibits phenomenological particularity.

The naïve realist is thus well set to explain why (1)-(3) are faithful descriptions of the phenomenology of Jaya's experience. It visually appears to Jaya as if that apple is there, partly because the very thing in question is a phenomenology-constituting constituent of her experience. And it visually appears to Jaya as if that apple is red (that looks red to her) partly because the thing in question, that, is a phenomenology-constituting constituent of her experience. Thus, the naïve realist's answer to the

${ }^{3}$ The naive realist is thus not committed to pure phenomenal particularism, in the terms of (Mehta 2014). 
explanatory question of why the particularity of Jaya's experience is reflected in its phenomenology falls out of the constitutive account they give of the phenomenology of experience.

From here on we will assume that the naive realist is committed to the explanation of phenomenological particularity just sketched out. References to 'naïve realism', 'the naïve realist', etc should be understood accordingly. Naïve realism looks well placed to provide an account of the particularity of experience. But many have thought that it cannot provide an account of the generality of experience. We turn to this in the next section.

\section{Phenomenological Generality}

Consider now Jaya on the following day. A creature of routine, Jaya glances over towards her desk and sees on it her mid-morning snack: another apple. There's nothing abnormal about the perceptual conditions or situation, and there's nothing abnormal about Jaya's perceptual capacities. This is not a "bad case", it's a straightforward veridical visual perception: she simply sees this apple for what it is. She thinks, "I'm going to eat that", making reference in her thought to the very apple in question.

Jaya has a visual experience of a particular entity: a particular apple, not just some apple or other but that one. And her experience exhibits phenomenological particularity. But this apple is qualitatively identical to yesterday's apple; the two apples are identical twins. And her experience of this apple has something in common with her experience of that apple, the one she was looking at yesterday. Her experience exhibits 'generality' (McGinn, 1982, p.39): things seem the same to Jaya in both these experiences. (One might deny this claim, but we will not explore this idea here).

A theorist of experience needs to explain why things seem the same to Jaya in these experiences. But this seems to confront the naïve realist theorist of experience with a challenge. The naïve realist emphasizes a difference in phenomenology between E1 (Jaya's experience of the first apple, a1) and E2 (Jaya's experience of the second apple, a2): for E1 and E2 each exhibit phenomenological particularity, but with respect to distinct particulars. How, then, can a naïve realist explain the fact that things seem the same to Jaya in E1 and E2, a fact which suggests that they are in some sense phenomenologically the same? We will understand this 
as the demand to explain the generality of visual experiences (Mehta 2014, Schellenberg 2010, p.29).

The challenge to explain the generality of experience looks similar to a challenge which has been raised for the naïve realist concerning hallucination. For consider E1 and now E3, a causally matching ballucinatory experience. The naïve realist claims that E1 and E3 are phenomenologically different. For the phenomenology of E1 is constituted by acquaintance with a mind-independent particular, whereas that is not how things are with E3. But - it is claimed - in E1 and E3 things seem the same to the subject. How can the naïve realist explain why things seem the same to the subject in E1 and E3 given the fact that they take there to be a phenomenological difference between them?

One way to address this challenge is to hold that there is nothing more to the phenomenology of the relevant hallucination than that of being introspectively indiscriminable from the corresponding visual perception (Martin 2004, 2006). Now we don't want to discuss the merits of this response to the challenge about hallucination - our focus here is not hallucination. But we do want to point out that it is not plausible that this strategy can be extended to the challenge of identical twins that is our concern here. For if we apply the strategy, then we will answer the question of why E1 and E2 seem the same to Jaya by claiming that there is nothing more to the phenomenology of E2 than that of being introspectively indiscriminable from that of E1. But this is clearly not a plausible thing for a naïve realist to say about E2. For there is more to the phenomenology of E2 than that of being indiscriminable from that of E1: its phenomenology is (partly) constituted by a relation of acquaintance that Jaya stands in to a mind-independent particular. Moreover, there are no obvious grounds for prioritizing E1 over E2 in the order of explanation, as this move does - prioritizing either one of the pair would be arbitrary. We cannot apply the response to the challenge from hallucination to the case of identical twins.

We should, then, sharply distinguish the challenge which is posed to naïve realism from hallucination and the challenge which is raised from issues to do with particularity and generality (c.f., Schellenberg 2010, p.29). Our focus here is just on the fact that things seem the same to the subject in the pair consisting of E1 and E2 - more generally, that things seem the 
same to the subjects in what we'll call Q-pairs, pairs of introspectively indiscriminable veridical experiences of qualitatively identical but numerically distinct particulars. ${ }^{4}$

\section{Phenomenal Character and Phenomenal Nature}

Given what they say about phenomenological particularity, how, then, can the naïve realist explain why Q-pairs exhibit generality, why things seem the same to the subject of the experiences in these pairs? We think the naïve realist can meet the explanatory challenge here by making a distinction between the phenomenal nature of an experience and the phenomenal character of an experience. The generality of experience is explained by the fact that the experiences in Q-pairs have exactly the same phenomenal character. In this section, we'll spell out what this means, and how it is consistent with the naïve realist account of phenomenological particularity. To do so, we adapt and develop the framework for thinking about the phenomenology of experience offered to intentionalists in Martin (2002).

\subsection{Explaining Generality in terms of Sameness of Phenomenal Character}

Martin (2002) conceives of the phenomenal character of an experience as a general attribute of an experience, something that is repeatable or shareable (p.194). Thus, the phenomenal character of an individual experience is a feature of the experience that could, in principle, be shared by numerically different experiences. He elaborates on this basic conception further by putting things in terms of qualities. He identifies the phenomenal character of a given experience as that which it has in common with qualitatively the same experiential events' (p. 194), where to consider an experience in terms of its qualities or qualitatively is to abstract away from any particulars the experience may involve (p.187). Thus, the phenomenal character of an individual experience could, in principle, be shared not only by numerically different experiences, but by numerically different experiences of numerically different objects.

\footnotetext{
${ }^{4}$ By 'introspectively indiscriminable' we mean in principle introspectively indiscriminable, that is, where the experiences are not just indiscriminable because of some contextual or contingent feature, but indiscriminable per se. For more on this, see section 6.1 below.
} 
With this notion of phenomenal character, we can address the demand to explain the generality of visual experiences. Consider Martin's own illustrative example. Take Huey and Dewey, qualitatively identical rubber ducks. Now take $\mathrm{H}$, the experience of Huey, and $\mathrm{D}$ the introspectively indiscriminable experience of Dewey. $\mathrm{H}$ and $\mathrm{D}$ seem the same to the subject of them. How to account for that? Well, $\mathrm{H}$ and $\mathrm{D}$ have exactly the same phenomenal character. To specify this phenomenal character, we abstract away from any particulars these experiences involve and consider just their qualities. And to simplify, suppose that the only relevant quality here is the 'presenting of a yellow, duck-shaped object' quality (Martin, p.187). Since $H$ and $D$ share this quality, they are both presentings of a yellow, duck-shaped object, and thus they have exactly the same phenomenal character. These experiences thus differ in phenomenal kind from qualitatively different experiences, such as those which have not the aforementioned quality but qualities like 'presenting of a red, duck-shaped object' or 'presenting of a yellow, pig-shaped object'.

The explanation of why things seem the same to the subject in $\mathrm{H}$ and $\mathrm{D}$, and for why $\mathrm{H}$ and $\mathrm{D}$ are thus introspectively indiscriminable is that they have exactly the same phenomenal character. A similar story can be told for Q-pairs generally.

\subsection{Particularity and Phenomenal Nature}

But one might worry that this move is not open to the naïve realist, given that they want to account for phenomenological particularity in the manner set out above. For if we conceive of the phenomenology of an experience in terms of its phenomenal character, then we are conceiving of phenomenology qualitatively and thus in abstraction from any particulars involved in experience. And this is at odds with the above naïve realist explanation of phenomenological particularity. Indeed, it eschews phenomenological particularity altogether.

An assumption here is that the phenomenology of an experience is to be identified with its phenomenal character. However, this assumption can be rejected. And this, we take it, is one of the lessons of Martin's discussion. As we interpret it, we are to think of the phenomenology of an experience, what it is like for a subject to undergo an experience, as having two dimensions, only one of which is phenomenal character. The other is 
what Martin calls phenomenal nature. The generality of visual experience is captured along the phenomenal character dimension of phenomenology, particularity is captured along the phenomenal nature dimension.

But what is phenomenal nature? An experience's phenomenal nature is, according to Martin, what makes 'room for the essentially or inherently particular aspects' of experience (p.192). It is an 'unrepeatable aspect' of perceptual phenomenology, an aspect of it which is 'proprietary to it as an individual, unrepeatable event' (p.175). Moreover, a given experience's phenomenal nature is partly individuated by the particular object or objects the experience is of (p.187). Applying these ideas to E1, for example, yields the following: the phenomenal nature of E1, PN1, is an unrepeatable dimension of E1's phenomenology which makes room for its inherently particular aspects, and which is tied to and partly individuated by the particular that E1 is an experience of, namely, a1. This means that similar or indiscriminable experiences of distinct entities will not have PN1: they will have distinct phenomenal natures which don't involve $\mathrm{a} 1 .^{5}$

We are now in a position to clarify the naïve realist account of particularity. We put things above in terms of the 'phenomenology' of experiences, but we can now be more specific. The naïve realist holds that the phenomenal nature of Jaya's experience of $\mathrm{a} 1$, and thus the phenomenology of Jaya's experience of a1, is partly constituted by Jaya's acquaintance with a1 itself. Thus, the naïve realist can claim that the

${ }^{5}$ For our purposes here, the crucial point is that the distinct experiences of distinct entities differ in phenomenal nature, even if they are otherwise similar, or in principle introspectively indiscriminable, such that an experience which is not of a1 will not have PN1. Now, since Martin takes the phenomenal nature of an experience to be 'proprietary to it as an individual, unrepeatable event' (p.175), it looks as though Martin thinks that the phenomenal nature of a particular experience is unrepeatable in the sense of being unique to that experience - and thus not shared by any other experience. Thus, Martin's discussion also seems to suggest that even different experiences of a1 will not have PN1, but they will have distinct a1-involving phenomenal natures. That's why, in applying Martin's notion of phenomenal nature to E1, we used the qualifier 'partly' in saying that the phenomenal nature of E1 is individuated by a1. If it were merely a1 which individuated the phenomenal nature of E1 then it is not clear why that nature would be unrepeatable: for there can be different experiences of a1. Presumably, then, on Martin's view, whatever else makes E1 the unrepeatable event it is, such as perceptual context (i.e., conditions and circumstances of perception), place, time etc also individuate the phenomenal nature of E1. We will remain neutral on the question of whether distinct experiences of a1 have distinct phenomenal natures: for our purposes, all that matters is that the phenomenal nature of a particular experience of certain particulars is not shared by distinct experiences of numerically different particulars. 
particularity of Jaya's experience E1 is reflected in its phenomenology because the phenomenology of her experience, in particular its phenomenal nature, is constituted in part by her being acquainted with the particular in question such that the particular itself is part of what constitutes what it is like for her to experience as she does. And a similar story applies to E2, Jaya's experience of a2. E2 will have an a2-involving phenomenal nature, namely, PN2, individuated in part by a2, and constituted in part by Jaya's acquaintance with a2.

Thus, the naïve realist can capture the phenomenological difference between $\mathrm{E} 1$ and $\mathrm{E} 2$ in terms of their distinct phenomenal natures, PN1 and PN2, the former being a1-involving, the latter being a2-involving. And this applies to Q-pairs more generally.

\subsection{The Relation Between Phenomenal Character and Phenomenal Nature}

The discussion of phenomenology and particularity which we have drawn from Martin was originally applied in the context of how an intentionalist can account for both particularity and generality. We have adapted Martin's discussion in the present context by applying it to the question of how a naïve realist can account for both particularity and generality. But what more can we say about the relationship between phenomenal character and phenomenal nature? We now want to adapt and develop Martin's framework further by discussing this question. (We don't assume that Martin would agree with any of the discussion to follow.)

Let's lift some of the simplification in play so far and elaborate on the naïve realist account of $\mathrm{E} 1$ and its phenomenal nature. In this experience, Jaya is consciously acquainted with, and thus perceptually presented with a particular object: a red apple. Let's suppose she is also acquainted and thus perceptually presented with its colour and shape: the redness of the apple, and the apple-shapedness of the apple. The naive realist can take this complex structure of acquaintance to be (part) constitutive of the phenomenal nature of E1, PN1. But then, in virtue of this complex phenomenal nature, E1 has the phenomenal character it has, call this PCE: namely, it is a presenting of a red, apple-shaped object. ${ }^{6}$ The phenomenal

\footnotetext{
${ }^{6}$ This still involves a simplified specification of the phenomenal character of E1. But other aspects of phenomenal character, understood as qualitative character, will similarly be traceable to corresponding aspects of phenomenal nature. See fn. 8 below.
} 
character of E1 is, as it were, the qualitative shadow of its phenomenal nature. More generally, the naïve realist can claim that our (genuinely perceptual) experiences have the phenomenal characters they have in virtue of the phenomenal natures they have. Phenomenal characters are qualitative shadows of phenomenal natures.

To spell this out further, what explains the type of phenomenal character a genuinely perceptual experience of certain particulars has is the type or qualitative identity of its particulars. An experience of certain particulars has a phenomenal character of the type it has in virtue of the type or qualitative identity of the particulars involved in its phenomenal nature. To illustrate this, let's return to E1. In this experience, as noted, Jaya is acquainted with an apple, its redness and its apple-shapedness. E1 has the type of phenomenal character it has - it is a presenting of a red, appleshaped object - because of the type or qualitative identity of the particulars its phenomenal nature involves. E1 is a presenting of a red, apple-shaped object because the phenomenal nature of E1 involves the presenting of an instance of redness. E1 is a presenting of an apple-shaped object because the phenomenal nature of E1 involves the presenting of an instance of apple-shapedness.

\subsection{Putting the Distinction to Work}

We are now in a position to see how the naïve realist can make sense of why E1 and E2 have exactly the same phenomenal character, even though they have different phenomenal natures. ${ }^{7} \mathrm{E} 2$ has the type of phenomenal character it has - it is a presenting of a red, apple-shaped object - because of the type or qualitative identity of the particulars its phenomenal nature involves. E2 is a presenting of a red, apple-shaped object because the phenomenal nature of $\mathrm{E} 2$ involves the presenting of an instance of redness. E2 is a presenting of an apple-shaped object because the phenomenal nature of E2 involves the presenting of an instance of appleshapedness.

Thus, what accounts for the character of E1 is exactly the same as what accounts for the character of E2: the type or qualitative identity of the presented particulars. That is, E1 and E2 have exactly the same

7 Given this, phenomenal character is thus multiply realizable on the view we are sketching (Schellenberg (2010, p.30)). 
phenomenal character despite their different phenomenal natures, because the numerically different elements of their phenomenal natures which are involved in accounting for this sameness of character are type or qualitatively identical. ${ }^{8}$

\subsection{Nä̈ve Realist Phenomenal Character}

On the account we are sketching the phenomenal nature dimension of phenomenology constitutively depends upon those very particulars. But the phenomenal character dimension does not. Despite this, given the relation between phenomenal nature and phenomenal character, the view still involves a naïve realist conception of phenomenal character. How so?

We've been talking only about the phenomenal character of genuinely perceptual experiences of particulars. This is phenomenal character of a certain sort. Regarding phenomenal character of this sort, we've claimed that the type of phenomenal character that an experience has depends upon the type or qualitative identity of the particulars involved in the experience's phenomenal nature (more metaphorically, phenomenal character is the qualitative shadow of phenomenal nature). Accordingly, phenomenal character is such that an experience cannot have it unless it has a phenomenal nature involving particulars which correspond, in their

\footnotetext{
${ }^{8}$ Note that we have been focusing on the shared phenomenal character, being a presenting of a red, apple-shaped object. But one might think that there is a more fundamental aspect to the shared phenomenal character in E1 and E2: namely, that of seeming as if there is something red and apple-shaped present. And one might wonder whether this is explicable merely in terms of the type or qualitative identity of the particulars involved in the phenomenal natures of these experiences. After all, it seems possible that an experience could involve the very same particulars in its phenomenal nature, and thus have a presenting of a red, apple-shaped object character, yet not be one in which it seems to the subject as if there is something red and apple-shaped present (e.g., in certain sorts of illusions). And this might make one wonder whether, even when one has an experience where it does seem to the subject as if there is something red and apple-shaped present, this can be explained merely in terms of the type or qualitative identity of the particulars involved. Now the line of thought just sketched certainly deserves more scrutiny than we are giving it here. But suffice it to say that the idea that there are aspects of phenomenal character that aren't explicable in terms of phenomenal nature only follows (if at all) if we focus only on the particulars involved in E1's phenomenal nature, as we have been doing in this paper. But once we broaden our discussion to recognise the way in which facts about the subject of experience (Logue 2012), facts about the way or manner in which one is acquainted with the objects of experience (Soteriou 2013), and facts about the circumstances and conditions of perception (Campbell 2009, Brewer 2011) all affect an experience's phenomenal nature, then there remains the option of explaining this further aspect of phenomenal character in terms of the experience's phenomenal nature, understood as involving further specification along each of these dimensions.
} 
type or qualities, to the type of phenomenal character in question. For instance, take PCE: being a presenting of a red, apple-shaped object. No experience can have this phenomenal character unless it has a phenomenal nature (such as PN1 or PN2) involving appropriate particulars (e.g., a red apple or a red apple-shaped object, an instance of redness, and appleshapedness, etc).

Given that the particulars we are focusing on here are mind-independent, we take this to encode a naïve realist conception of phenomenal character. Take an experience with phenomenal nature PN1 and phenomenal character PCE. It follows from our conception of phenomenal character that no experience could have PCE unless it involved the perception of a mind-independent object which is of the same type or qualitative profile to mind-independent objects which constitute PN1. This doesn't mean, then, that PCE depends upon the very objects seen in this particular case. It does mean, though, that if an experience is to have that character it must involve perception of some such mind-independent particular. The difference is between dependence upon this mind-independent object and dependence upon such a mind-independent object as this (cf. Martin 2006).

Thus, on the naïve realist view we are developing, both phenomenal nature and phenomenal character depend on mind-independent objects; it's just that the dependence on mind-independent objects in each dimension is different. ${ }^{9}$

\subsection{Summary: Nä̈ve Realist Particularism}

We have suggested that the naive realist should explain the particularity of perceptual experiences in terms of the phenomenal nature of perceptual experiences, and the generality of perceptual experiences in terms of the phenomenal character of perceptual experiences. (We are focusing only on

\footnotetext{
${ }^{9}$ One consequence of this is that our view inherits the usual commitments of naive realism regarding hallucination. Recall E3. Given that E3 doesn't have a phenomenal nature involving any mind-independent particulars, it doesn't have phenomenal character of the sort that E1 and E2 has. It doesn't have PCE or any such naive realist phenomenal character. Thus, for causally matching hallucinations, it looks like we are committed either to some sort of disjunctivism about phenomenal character (Martin 2004, 2006), or else to some sort of eliminativism about hallucinatory character (Fish 2009). Many will find this consequence problematic. But it strikes us a feature of the naive realist framework, and not a special problem to do with the framework as developed with respect to particularity or generality. We thus set it aside in what follows.
} 
genuinely perceptual veridical experiences of particulars, in the visual modality). And we have set out what a naïve realist should say about what makes it the case that such experiences have the characters they do. The naïve realist account we have offered is that an experience has its phenomenal character in virtue of its phenomenal nature. We have spelled this out further by claiming that the type of phenomenal character an experience has will depend upon the type or qualitative identity of the mind-independent particulars involved in the phenomenal nature of the experience. This view involves naïve realist accounts of both phenomenal nature and phenomenal character.

One can certainly be a naïve realist and not endorse all of what we've sketched out here. Thus we'll call the position we've developed naïve realist particularism to mark it out from other versions of naïve realism.

\section{The Self-Knowledge Argument}

Naive realist particularism has it that Q-pairs are both the same and different phenomenologically. This is possible insofar as phenomenology has two dimensions, phenomenal nature, where they differ, and phenomenal character, where they are the same. The pairs differ in phenomenal nature in virtue of involving numerically distinct particulars, they are the same in phenomenal character in virtue of involving qualitatively identical particulars.

We are now in a position to consider and elaborate an argument against this position which concerns the kind of knowledge we have of the phenomenology of our own visual experiences. We'll call this the selfknowledge argument against naive realist particularism. We'll set out the argument in 6.1 and explain how the naïve realist particularist can respond in 6.2 .

\subsection{Formulating the Self-Knowledge Argument}

To build up to this argument we need first to outline a principle we find in Schellenberg (2010) and Montague (2016). Consider first Schellenberg:

Positing such object-dependent and unrepeatable phenomenal natures entails that any two experiences of distinct objects necessarily differ 
phenomenally; even if the relevant objects are qualitatively indistinguishable. This consequence is counterintuitive as a thesis about phenomenology. It is counterintuitive even if one acknowledges that two experiences can exhibit a phenomenal difference while being subjectively indistinguishable. Granted it is plausible that two experiences could be subjectively indistinguishable despite phenomenal differences between the experiences due to minute differences in the perceived colors or shapes. Such differences are, however, at least in principle subjectively accessible since there is a qualitative difference between the perceived the colors or shapes. We would detect the differences, were our sensory apparatus better. The case of numerically distinct but qualitatively indistinguishable objects is different, since in this case there is no qualitative difference between the perceived objects. We could not detect a difference, even if our sensory apparatus were perfect. So accepting the possibility of such differences in phenomenology that are not subjectively accessible requires accepting that there can be aspects of phenomenology that are in principle not subjectively accessible to the experiencing subject (pp.30-31).

Applying Schellenberg's worry to our Q-pair, the point is that however perfect Jaya is as a perceiver, however perfect her sensory apparatus, however perfect the conditions of perception, the phenomenological difference between her experience of a1 and her experience of a 2 that the naïve realist particularist posits is subjectively inaccessible to her. The two experiences are not merely contingently or contextually subjectively indiscriminable; they are in principle subjectively indiscriminable, and that, according to Schellenberg, is problematic.

Montague may have a similar argument in mind in the following passage. Her focus is Martin's (2002) account, but the criticism carries over to naïve realist particularism too. She argues as follows:

... According to Martin, the phenomenal nature of an experience is the presentation of a particular physical object. Consider the sense in which 'being present' is meant to be a phenomenological notion. According to Martin, if a physical object does not constitute part of the phenomenology of an experience it is not present in experience. There is, however, a clear sense in which physical objects do not constitute part of the phenomenology of experience. If veridical perceptions and their corresponding hallucinations can indeed be subjectively indistinguishable, then 'qualitative content', in Martin's terms, accounts entirely for the phenomenology of these experiences. So physical objects, as such, do not play a role in determining the phenomenology of veridical perceptions. If physical objects did play such a role, given that they are extra ingredients in veridical perceptions, then it seems there would have to be detectable 
phenomenological differences between veridical perceptions and their corresponding ballucinations (pp. 132-133, emphasis added).

The crucial move in the above seems to be the segment we have emphasised. Montague makes her claim in the context of discussing the relation between veridical perceptions and their corresponding hallucinations, but we will reformulate the argument in terms of the experiences of qualitatively identical twins since, as noted above, it sharpens the force of the challenge. The reformulated version of Montague's claim has it that if the experiences of qualitatively identical twins are subjectively indiscriminable, then the particular objects perceived in each case cannot play a role in determining the phenomenology of each experience. And the reasoning seems to be that they cannot play such a role because if they did, then the phenomenological difference between the experiences would be detectable contrary to our initial supposition. And though she doesn't say precisely what she means by 'detectable', and she sometimes speaks of 'phenomenological' detection, and she doesn't explicitly draw on introspection as Schellenberg does (c.f., Schellenberg, p. 29), we interpret Montague's discussion in terms of introspective detectability. Accordingly, the idea seems to be that phenomenological differences between Q-pairs must in principle be introspectively detectable, that is, detectable by introspection on the phenomenology of the experiences.

Schellenberg and Montague seem, then, to endorse the following principle:

The Phenomenological Differences Principle (PDP)

Phenomenological differences between Q-pair experiences must be in principle detectable by means of introspection. ${ }^{10}$

And a straightforward argument against naïve realist particularism is that it falls foul of (PDP).

\footnotetext{
${ }^{10}$ Here 'phenomenological' covers both character and nature. And note again that the notion of 'being in principle undetectable' rules out explanations of the introspective indiscriminability which turn on the cognitive limitations of the agent, for the question is not about whether there can be phenomenological differences which are undetectable for this or that agent, given her particular context etc., but whether there can be phenomenological differences which are undetectable tout court. We will assume this impersonal conception of being undetectable in what follows. On which see Martin (2006).
} 
One problem here, though, is that (PDP) is not self-evident, and as far as we can tell Schellenberg and Montague do not do any substantive work to support it. Absent any argument or motivation for (PDP), the naïve realist particularist can claim that their view does conform to (PDP), but that this is just a consequence of their view, not a problem with it.

Let us consider, then, the reasons to endorse (PDP). (PDP) is most plausibly supported by a more general thought about the way in which the phenomenology of perceptual experiences interacts with our knowledge of the phenomenology of our perceptual experiences. That is, lying behind the principle is a view about the relation between the phenomenology of perceptual experiences and our introspective knowledge of that phenomenology. Consider the fact that, as conscious subjects, we are often in a position to know something about the phenomenology of our perceptual experiences. This knowledge plays a role in philosophical theorising about the nature of perceptual experience. Questions about the character, source, and limits of our knowledge of the phenomenology of perceptual experience are thus relevant to discussions about the phenomenology of perceptual experiences.

This raises the following question: does the nature of the introspective knowledge we have of the phenomenology of our perceptual experience place any constraints on our accounts of the nature of perceptual experience? (PDP) expresses such a constraint: it holds that phenomenological differences between Q-pair experiences must be in principle introspectively detectable - which is to say, knowable on the basis of introspection. And one might try to motivate (PDP) by appeal to a more general link between phenomenology and knowledge of phenomenology. We call this the Self-Knowledge Principle:

\section{The Self-Knowledge Principle (SKP)}

There cannot be aspects of phenomenology which are in principle introspectively unknowable.

According to (SKP), all aspects of phenomenology are in principle introspectively knowable. If the phenomenological differences between pairs of experience are aspects of phenomenology, they too must be in principle introspectively detectable. So a commitment to the (SKP) explains why someone would hold (PDP). 
But why would someone endorse (SKP)? One thought is that the phenomenology of a perceptual experience just is the way in which things seem to the subject when she undergoes that experience (McGinn 1982, pp.9-10). And how things seem to a subject is an aspect of her conscious life. But there cannot be aspects of a subject's conscious life which are in principle inaccessible to her. We can make sense of there being aspects of the external world which are forever beyond us. But our conscious life seems too intimately connected to us to be forever closed off in this kind of way.

However, the problem with motivating (PDP) via (SKP) is that (SKP) places a luminosity constraint on phenomenological aspects, and Timothy Williamson's anti-luminosity argument (2000, ch.4) poses an influential challenge to any such constraint. Thus, it is open to the naïve realist particularist to adopt some such argumentative strategy to reject (SKP), and thus undercut the support we have found for (PDP). Indeed, some naïve realists already reject such luminosity constraints. For instance, in responding to the problems caused by hallucinations Matthew Soteriou suggests that the naïve realist acknowledge that 'we are not infallible when it comes to making judgements about the phenomenal character of our own experiences. We need to accept a more modest view of the extent to which we can know our own minds and mental lives. Not even the phenomenal properties of our own mental events are luminous' (2013, p.199).

Is there an alternative way of motivating (PDP) which doesn't involve a commitment to luminosity? Although (PDP) follows from (SKP), together with the assumption that phenomenological differences are aspects of phenomenology, the opponent of naïve realism need not accept (SKP) in its full generality. That is, they might deny that (SKP) is a general truth about the link between aspects of phenomenology and introspective knowability, whilst holding that there are still good reasons to think that a restricted version of the principle holds in the case at hand. That is, the opponent of naïve realism may take there to be something problematic about the denial of (SKP) in this particular case.

Why would the denial of (SKP) be particularly objectionable in the cases under consideration? Williamson's argument against luminosity principles turns on the failure of luminosity in borderline cases. So someone who is 
sympathetic to Williamson's argument might see the case for denying that aspects of phenomenology are always introspectively knowable in borderline cases. But this wouldn't entail that there could be aspects of phenomenology which were in principle introspectively unknowable in non-borderline cases (Hawthorne 2005). And the cases of qualitatively identical but numerically distinct twins that we have been concerned with do not seem to be borderline or odd in some other way which would be relevant for the general denial of (SKP). Thus, it looks like it is the plausibility of (SKP) for the cases at hand which motivates (PDP). ${ }^{11}$

Given this, we are now in a position to formulate the Self-Knowledge Argument against naïve realist particularism which utilizes a Restricted Self-Knowledge Principle. The argument runs as follows:

\section{The Self-Knowledge Argument}

1. Naïve realist particularism entails that there can be phenomenological differences between Q-pair experiences which are in principle undetectable by means of introspection.

2. If there can be phenomenological differences between Q-pair experiences which are in principle undetectable by means of introspection, then there can be aspects of the phenomenology of the experiences in Q-pairs which are introspectively unknowable.

3. Restricted Self-Knowledge Principle (RSKP): There cannot be aspects of phenomenology which are in principle introspectively unknowable in Q-pairs.

Therefore,

4. Naïve realist particularism is false.

How should the naïve realist particularist respond to this argument?

\subsection{Rejecting the Self-Knowledge Argument}

\footnotetext{
${ }^{11}$ This reinforces our decision to focus solely on the case of identical twins here because, once again, they raise a more difficult problem for naïve realism than the case of causally matching hallucination. Hallucinations might be thought to be sufficiently odd that the denial of the Self-Knowledge Principle can be motivated for such experiences but, again, on the face of it, it seems much less compelling to make that move for the case of identical twins.
} 
One strategy for responding to this argument is to reject even (RSKP). But a naïve realist who opts for this strategy owes us an explanation of why it is that (RSKP) is false. And we have suggested above that the reasons for thinking that the more general (SKP) is false don't obviously carry over to the restricted version. Our aim in this section is to show how the argument can be rejected without denying (RSKP).

Let us start with (1). This claim states that naïve realist particularism entails that there can be phenomenological differences between Q-pair experiences which are in principle undetectable by means of introspection. Is this true? We take the phenomenological difference between E1 and E2 to be a certain relation which holds between $\mathrm{E} 1$ and E2: most basically, it is the relation of being non-identical which holds between the phenomenal nature of E1 (which involves this apple), and the phenomenal nature of E2 (which involves that non-identical apple). On this understanding, it is true that naive realist particularism entails that there are phenomenological differences between experiences in Q-pairs (since it holds that the experiences have distinct phenomenal natures).

Does it follow that naïve realist particularism entails that there can be phenomenological differences between experiences in Q-pairs which are in principle undetectable by means of introspection? There are ways in which one might deny this claim, but we will accept it here. The reasoning runs as follows: when Jaya is undergoing E1, she is in a position to know that she is having an experience with a phenomenal nature involving that particular apple. And this is because the phenomenal nature of the experience is given to her in introspection. And when she is undergoing E2 she is in a position to know that she is having an experience with a phenomenal nature involving that (as it happens, distinct) apple. For this phenomenal nature is something which is given to her in introspection. But the relation between the two experiences is not itself something which is given in introspection. So she cannot come to know that the relation of nonidentity holds on the basis of introspection: there are phenomenological differences between experiences in Q-pairs which are in principle undetectable by means of introspection. ${ }^{12}$

\footnotetext{
${ }^{12}$ It is important here that the claim is that the phenomenological differences cannot be detected by means of introspection. For one might hold that knowledge requires ruling out relevant alternatives - in which case, Jaya's knowledge that she is having an
} 
This leaves us with (2). Let's call it the Linking Principle

\section{The Linking Principle (LP)}

If there can be phenomenological differences between Q-pair experiences which are in principle undetectable by means of introspection, then there can be aspects of the phenomenology of the experiences in Q-pairs which are introspectively unknowable.

Applying this to the case at hand, (2) says that if the phenomenological difference between E1 and E2 is introspectively undetectable, then there can be introspectively unknowable aspects of the phenomenology of these experiences. The principle here links unknowable differences in phenomenology to unknowable aspects of phenomenology.

The most straightforward way for this principle to be true would be if the phenomenological differences between experiences in Q-pairs were an aspect of the phenomenology of those experiences. But is this right? As we have just set out the nature of the differences in phenomenology, it doesn't make sense to suppose that the difference between E1 and E2 is an aspect of phenomenology. The difference in phenomenology is a relation that the two experiences stand in to one another, not an aspect of either individual experience. Differences between the phenomenology of two experiences should not themselves be thought of as aspects of phenomenology. (LP) is unsupported.

Perhaps part of the confusion here rests on a failure to adequately recognise the diachronic nature of the difference in question. For it might be plausible to think that phenomenological differences between synchronic parts of experiences must themselves be aspects of the phenomenology (perhaps when restricted to particular perceptual modalities). The left part of your visual field is redder than the right part of your visual field. This is a difference in phenomenology which obtains between parts of your

experience with the phenomenal nature PN1 requires that she be in a position to know that she is not having an experience with the phenomenal nature PN2; but that's just to say that she must be in a position to know that these experiences are distinct. Accepting premise 1 doesn't require one to deny this claim. Rather, it requires only that Jaya is not in a position to rule out the relevant alternatives on the basis of introspection. We take it that this is independently plausible - so if one wants to hold on to the relevant alternatives condition as a condition on knowledge, then one should take it that Jaya's capacity to rule out the relevant alternatives is not based in introspection. 
visual experience. But this difference is also itself an aspect of your phenomenology. The diachronic case is not like this: differences between the phenomenology of diachronic experiences need not themselves be aspects of the phenomenology.

Here is another way to put the point: the naïve realist can allow that there is a difference between how things seem to Jaya when she experiences a1, and how things seem to Jaya when she experiences a2. But it doesn't follow that it seems to Jaya as if there is a difference between her experience of a1 and her experience of a2. A difference in seemings is not a seeming difference.

To summarise: (LP) holds that if there can be phenomenological differences between experiences in Q-pairs which are in principle undetectable by means of introspection, then there can be aspects of the phenomenology of the experiences in Q-pairs which are introspectively unknowable. But the naïve realist particularist is not compelled to accept this claim. It is compatible with Jaya knowing all the aspects of her phenomenology of the experiences in Q-pairs that she not be able to know, through introspection, some fact about the relation between the experiences.

Is there anything that the proponent of (LP) can say in response? We have assumed above that the phenomenological difference between experiences in Q-pairs is a relation between the experiences in Q-pairs - and given that assumption, we have shown that such differences can be both introspectively unknowable and not aspects of phenomenology. But the proponent of (LP) might try to advance their case by employing an alternative understanding of phenomenological differences. Consider a nice example from Fred Dretske's discussion of change blindness (2004, pp.9-10). Your friend lacks a moustache. He later grows one. A difference between your friend at the earlier time and your friend at the later time is the moustache. One can perceive this, and thus perceive a difference, even without identifying it as such (one might not notice that one's friend differs in now having a moustache even if one sees the moustache, which is the difference). ${ }^{13}$ The moustache makes for a difference between your friend at $\mathrm{t} 1$ and your friend at $\mathrm{t} 2$. You get to perceive the difference by perceiving

${ }^{13}$ Dretske calls this the object model of differences, in comparison to the fact model (2004, p.

9). Our previous discussion could be recast in terms of the fact model. 
this difference maker. Call this the difference maker model of difference. On this account, perception of differences is perception of difference makers.

So now let's switch back to Q-pairs, in particular to E1 and E2, and to introspection. One difference maker between E1 and E2 is an aspect of the phenomenology of E2: namely that it has a particular phenomenal nature, it being a presentation of that apple a2. If phenomenological differences are the phenomenological difference makers, then the phenomenological difference between E1 and E2 - the phenomenal nature of $\mathrm{E} 2$ - is an aspect of phenomenology. (LP) is true.

The problem here is that if one understands phenomenological differences on the difference maker model, then although (LP) comes out as true, it becomes false that the relevant differences are introspectively unknowable. After all, if a phenomenological difference between E1 and $\mathrm{E} 2$ just is the phenomenal nature of E2, then there is no reason for a naïve realist particularist to deny that that aspect of the phenomenology of E2 is introspectively knowable. Jaya can know, when undergoing E2, that her experience is an experience of that apple. That is, this aspect of phenomenology, PN2, comes within the scope of her introspective knowledge. (LP) comes out as true, but the first premise of the SelfKnowledge Argument comes out as false. ${ }^{14}$ Either way, the argument fails.

To sum up, the naïve realist particularist can reject (2) of the SelfKnowledge Argument on an understanding of it on which the phenomenological differences between experiences in Q-pairs are relations between those experiences. Those relations may be introspectively unknowable, but as we've explained, for all that, the relevant aspects of phenomenology can still be introspectively knowable. And if we understand phenomenological differences between experiences in Q-pairs as difference makers, namely aspects of phenomenology, then a version of (2) is true, but - for the same reason - (1) will be false. Thus the naïve realist particularist can reject the Self-Knowledge Argument.

\footnotetext{
${ }^{14}$ This mirrors Dretske's remarks on the object model. If we do understand differences and cognition of them in these terms - and note, that Dretske doesn't endorse this model - then differences, as difference makers, can be seen, even if they can't be identified as such. So just as one might see a difference maker in seeing one's friend's moustache, even if one fails to know that they have changed, one might introspect a difference maker between experiences, in introspecting aspects of phenomenology, even if one fails to know that the experiences differ in phenomenology.
} 


\section{Conclusion: Introspective and Visual Indiscriminability}

We've argued that the naïve realist particularist can reject the SelfKnowledge Argument. And aside from the considerations to do with selfknowledge that we've scrutinized here, it is not obvious why we should accept (PDP), that phenomenological differences between Q-pair experiences must be introspectively detectable.

But have we said enough to defend naïve realist particularism? Normally phenomenological differences between experiences are introspectible. Jaya sees a tomato for what it is, and then later she sees a kangaroo for what it is. These experiences differ phenomenologically, and that is something that is introspectively accessible to Jaya. And the same holds for countless other pairs. And one might think that even if this doesn't establish (PDP) tout court, still it suggests that any deviation from the principle requires an explanation. And that places an explanatory burden on the naïve realist particularist: what is it which determines that the phenomenological differences between Q-Pairs are introspectively undetectable when phenomenological differences between experiences are normally introspectively detectable? One way to frame the challenge here is as follows. Sometimes the relations of diachronic phenomenological difference are introspectively accessible - even if they are never aspects of phenomenology. So why is it that we can't be introspectively given the non-identities which constitute the diachronic phenomenological differences in Q-pairs?

Our answer falls neatly out of our account of the particularity and generality of experience and showcases the central idea of a naïve realist account of perception. ${ }^{15}$ The phenomenological differences between Qpairs are not introspectible because the objects of the respective visual experiences are themselves qualitatively identical. Qualitatively identical objects are visually indiscriminable, and when two objects are visually indiscriminable we should expect that the visual experiences which involve those objects as constituents will themselves be introspectively indiscriminable. That is, the naive realist account of visual experience predicts that experiences of objects which are visually indiscriminable will themselves be introspectively indiscriminable. The impossibility of detecting the phenomenological differences between Q-pairs is explained

15 See (Brewer 2011, pp.98-99) for a similar line of thought. 
by the naive realist account of the relation between mind-independent objects and visual experiences and the resulting implications for the relations between visual and introspective discriminability.

Consider our example. Jaya's kangaroo experience has a phenomenal nature $\mathrm{KN}$, and her tomato experience has a phenomenal nature $\mathrm{TN}$. Introspective reflection can reveal these to be distinct precisely because they differ qualitatively - and the explanation of this is the fact that the relevant particulars are qualitatively non-identical. But this isn't true for Qpairs. PN1 and PN2 are numerically distinct but qualitatively identical phenomenal natures - and the explanation of this is the fact that the relevant particulars are qualitatively identical. It looks, then, like we have the following pattern of explanation. One cannot introspectively tell apart PN1 and PN2 because the particulars these natures involve are qualitatively the same. ${ }^{16}$ But one can introspectively tell apart KN and T1 because the particulars these natures involve are qualitatively different.

And this mirrors the situation for perceptual knowledge. One cannot perceptually tell apart this apple and that apple because they are qualitatively identical, but one can perceptually tell apart this kangaroo from that tomato, because they are qualitatively non-identical. It is the visual indiscriminability of the objects involved in Q-pairs which explains the introspective indiscriminability of the experiences in Q-pairs. We have a principled explanation as to why (PDP) fails in cases of Q-pairs, one which turns on a naïve realist account of the relation between objects and experiences.

Once we see the connection between visual discrimination and introspective discrimination, the nature and bounds of our introspective knowledge of visual experiences becomes clearer. We have argued above that introspection is constrained when it comes to knowing certain phenomenological differences, but that this is compatible with introspection allowing knowledge of phenomenal natures. Similarly, the fact that Jaya cannot tell this apple apart from that apple on the basis of perception shows that there is a limit to her perceptual knowledge. But it doesn't follow from this that Jaya cannot have perceptual knowledge of the very particulars in question. She can perceptually know, for instance, that this exists, and that that exists, even if she cannot tell this and that apart. Limits

${ }^{16}$ Holding fixed any other aspects of the phenomenal natures. See fn. 8 above. 
to introspective knowledge concerning the differences between things no more imply limits to introspective knowledge of things which are different than limits to perceptual knowledge concerning the differences between things imply limits to perceptual knowledge of things which are different.

We have argued in this essay that the naïve realist can provide a compelling account of both the particularity and the generality of experience. And we have argued that in doing so, the naïve realist is not committed to denying any principle about the impossibility of aspects of phenomenology which are in principle inaccessible. Moreover, the limits to introspection to which the naïve realist is committed are limits which are explained by the limits to perception which arise when we perceive qualitatively identical but numerically indistinct things. The naive realist account of visual experience predicts a limit to introspection without being committed to there being aspects of phenomenology which are everywhere and always beyond our ken.

This matters because many of those involved in these debates - both opponents and defenders of naïve realism - sometimes assume that naïve realism implies some kind of restriction on the kind of knowledge subjects can have of the phenomenology of their own experiences. This seems to us too hasty a conclusion. There is something which perceivers cannot come to know about their experiences on the basis of introspection - namely, something about the relations between their experiences and other experiences. But this is compatible with subjects knowing all there is to know about the phenomenology of their experiences. Neither the naïve realist's explanation of the particularity of experience nor the naïve realist's explanation of the generality of experience pose a threat to the kind of self-knowledge we can have of the phenomenology of our own perceptual experiences.

\section{References}

Brewer, Bill (2011). Perception and Its Objects. Oxford University Press. Campbell, John (2002). Reference and Consciousness. Oxford University Press. 
Campbell, John (2009). Consciousness and Reference. The Oxford Handbook of Pbilosopby of Mind. Ed. by Brian P. McLaughlin, Ansgar Beckermann, and Sven Walter. Oxford University Press, pp. 648-662.

Dretske, Fred (2004). Change blindness. Pbilosophical Studies 120 (1-3):1-18.

Fish, William (2009). Perception, Hallucination, and Illusion. Oxford University Press.

Hawthorne, John (2005). Knowledge and Evidence. Philosophy and Phenomenological Research 70 (2):452-458

Logue, Heather (2012). Why Naive Realism? Proceedings of the Aristotelian Society 112 (2pt2):211-237.

Martin, Michael G. F. (2002). Particular Thoughts \& Singular Thought. Royal Institute of Philosophy Supplement 51:173-214.

Martin, Michael G. F. (2004). The limits of self-awareness. Philosophical Studies 120 (1-3):37-89.

Martin, Michael G. F. (2006). On being alienated. In Tamar S. Gendler \& John Hawthorne (eds.), Perceptual Experience. Oxford University Press.

McDowell, John (1994). Mind and World. Cambridge: Harvard University Press.

McGinn, Colin (1982). The Character of Mind. Oxford University Press.

Mehta, Neil (2014). The Limited Role of Particulars in Phenomenal Experience. Journal of Philosophy 111 (6):311-331.

Montague, Michelle (2016). The Given: Experience and its Content. Oxford University Press UK.

Soteriou, Matthew (2000). The particularity of visual perception. European Journal of Philosophy 8 (2):173-189.

Schellenberg, Susanna (2010). The particularity and phenomenology of perceptual experience. Philosophical Studies 149 (1):19-48.

Schellenberg, Susanna (2016). Perceptual particularity. Philosophy and Phenomenological Research 93 (1):25-54.

Soteriou, Matthew (2013). The Mind's Construction: The Ontology of Mind and Mental Action. Oxford University Press.

Williamson, Timothy (2000). Knowledge and its Limits. Oxford University Press. 